\section{MEDICAL JURISPRUDENCE}

By I. Gordon, M.B., Ch.B., R. Turner, M.B. Ch.B., D.P.H., and T. W. Price, Ph.D., M.A., LL.B., 3rd Edition. Pp. lv + 944, with 143 illustrations, some in colour. Edinburgh : E. \& S, Livingstone Ltd. $1953.75 \mathrm{~s}$.

This is not so much a third edition of the original 'Gordon, Rhodes and Turner,' which was designed for the novice, as an entirely new writing, so voluminous and comprehensive now as to place it quite beyond the requirements of all but the practising specialist in the subject. The table of contents alone occupies 33 pages of close print, and an index of some 450 law cases follows. Exactly a third of this book-30o-odd pages-is devoted to Union and Southern Rhodesian law and procedure, the work of the new legal author, Price, and a model of succinct statement.

The main two-thirds is devoted to the detailed practice and study of forensic medicine-toxicology is not included-and provides a remarkably good review of the subject. It is distinguished by some excellent writing on anoxic death (by Gordon and Turner), on regional head injuries (following Moritz and Rowbotham), and on alcoholic intoxication, some surprisingly mediocre work on identity by anatomists Drennan and Keen, and some inadequate handling of important subjects like abortion and neonatal death.

The book is authoritative for it is the work of experienced and well-read authors who have drawn extensively on world literature in the subjectindeed, we could wish that South Africa's statistics on the subject entered more freely into the text. We deliberately avoid combing for error-or difference of opinion, for in such a vast work both must exist; suffice that this is a most ambitious work remarkably well carried out, comprehensive and quite well illustrated, if a little unevenly. Its law is designed solely for the South African, and its standard is plainly set well above the head of the student or the practitioner. It is a book of South African forensic medicine for reference, a review of world literature and an excellent guide for the district surgeon and the lawyer as well as a companion to the lecturer in the subject; one of the most informed books that has yet appeared.

\section{DIETETIC TABLES}

Compiled by G. F. WALKeR, M.D., F.R.F.P.S., D.C.H., M.R.C.P. Bristol: John Wright \& Sons, Ltd.

This useful card gives in an easily understood manner the caloric value and the amount of carbohydrate, fat and protein in various common foods. It should be most useful to both the diabetic patient in choosing articles for his own diet and to the physician when giving advice on this subject.
THE FABER MEDICAL DICTIONARY

Edited by Sir Cecil WaKeley, Bt., K.B.E., 市 C.B., Ll.D., M.Ch., D.Sc., F.R.S.E., F.R.A.C.S., F.A.C.S., F.R.S.A., F.Z.S. Pp. vii +471. London: Faber and Faber Ltd. 1953. 45s.

A dictionary should be accurate, comprehensive? and comprehensible. It should open easily and bee of managable proportions. It should be a fascinat $-\frac{\bar{\sigma}}{\bar{n}}$ ing book to browse through even though its contents? are largely technical.

The style of the new Faber Medical Dictionaryon is a model of brevity and simplicity and its guides to pronounciation can be appreciated at a glance. 0 How comprehensive it is can only be learned by experience but no important omissions have been found by the reviewer. The students of the presento day for whom Anatomy has been shorn of its propef names will appreciate especially their inclusion here for clinicians are slow to abandon the old nomen- $\mathbb{C}$ clature.

On balance there is much to recommend this $\omega_{\infty}$ new work but the high cost of production theseos days is reflected in a price similar to that of revised editions of older and more lengthy works and ino paper and binding unusual in a medical reference book. The illustrations are strangely few in a dictionary intended to cover, according to the foreword, the needs of the laity working in the National迎 Health Service, and there are no tables, not even बfo pharmaceutical weights and measures.

\section{GENERAL PATHOLOGY FOR STUDENTS OA DENTISTRY}

By G. L. Montgomery, T.D., M.D., PhD., F.R.F.P.S.G., F.R.S.E. Pp. 305 with 133 illustrations. Edinburgh: E. \& S. Livingstone Ltd.ō 1953. 37s. 6d.

The amount of knowledge that must be as- $\stackrel{\mathbb{D}}{\Omega}$ similated by the student of today makes it important $\overrightarrow{\vec{A}}$ to present the basic facts in as simple and concise 3 a manner as possible. Each year more is added $\supset$ to the sum of knowledge whilst the available time to learn for examination purposes is not increased. It has to be appreciated that only the groundings can be learnt prior to qualification and that deeper:and more extensive knowledge comes with ex- $\frac{3}{3}$ perience, practice and need.

This new textbook is therefore to be welcomedô for its approach to the problem of teaching. Prof. Montgomery has sought to condense into readable응 form the fundamental principles of pathology with the accent on what the future dental surgeon willo require in his everyday work. He has not encroached on the field of dental pathology as such, $\mathbb{N}$ but has made it possible for the student to gain an insight into the manner in which disease of the oralo cavity and associated parts is linked intimately andw indissolubly with disease of the whole body.

The production is up to the high standardo associated with this publishing house and the booke can be recommended without hesitation for anyone $\stackrel{0}{\rightarrow}$ reading for a qualifying degree or diploma.

S.R. 